\title{
Intramural fibroma of the left ventricle
}

\author{
J OH N I. H A L L \\ Department of Cardiology, Royal Infirmary, Edinburgh
}

\begin{abstract}
A case of left ventricular fibroma in a symptomless 17-year-old girl is described. The tumour was extensive and after its removal inadequate left ventricular function resulted in death at operation. The role of surgical treatment is discussed.
\end{abstract}

Primary tumours of the heart are rare (Prichard, 1951 ; Hudson, 1965 ; Heath, 1968) and particularly uncommon is the intramural ventricular fibroma ; only 36 cases had been reported up to 1967 (Geha, Weidman, Soule, and McGoon, 1967). Most of these intramural fibromas were found in infants and young children at either necropsy or thoracotomy, but over the past 15 years the diagnosis has been made before operation and in a few patients successful surgical removal has been accomplished (Parks, Adams, and Longmire, 1962; Geha et al., 1967 ; Björk, Dahlgren, Rudhe, Zetterqvist, 1967 ; Kay et al., 1968 ; Osano et al., 1969).

Because of the rarity of these tumours Freeman, Geer, Randall, and Palfrey (1963) suggested that cases should be reported in order to increase knowledge of their natural history, diagnosis, and treatment. The case described here is that of a young girl with a large intramural fibroma of the left ventricle, diagnosed preoperatively, who died at operation.

\section{CASE REPORT}

The patient, a 17-year-old girl, was referred to the Department of Cardiology, Royal Infirmary, Edinburgh, by her general practitioner who had detected a precordial systolic murmur at routine medical examination.

She was asymptomatic and apart from common childhood illnesses her previous health had been excellent. On specific enquiry, however, she had noticed occasional 'missed beats' during the preceding few months.

She was of average build with sinus arrhythmia and a systemic blood pressure of $115 / 60 \mathrm{mmHg}$. The jugular venous pulse was normal. There was no cardiomegaly and no thrill, but systolic pulsation was palpable at the upper left sternal edge. Heart sounds were normal with inspiratory splitting of the second heart sound and no accentuation of the pulmonary component. A short grade $2 / 6$ mid-systolic murmur was heard in the pulmonary area but was not audible in the axillae or over the back. No ejection sound, diastolic murmur or other abnormal physical sign was detected.

The electrocardiogram (Fig. 1a and b) showed sinus arrhythmia with occasional ventricular extrasystoles and symmetrical inversion of the $T$ waves in the high anterolateral leads. Her chest radiograph (Fig. 2) showed a localized bulge on the upper left heart border. Pulmonary arteries and pulmonary vascularity were normal. No calcification was detected at fluoroscopy. The full blood picture, blood urea, electrolytes, and plasma proteins were normal.

At cardiac catheterization pressures and oxygen saturations on the right and left sides of the heart were normal. Cine-angiography, performed from the right and left ventricles, demonstrated a large mass encroaching on the outflow tract of both ventricles and displacing the interventricular septum to the right. The left atrium was also distorted and the left atrial appendage was not filled with contrast medium.

A tumour of the left ventricular wall was diagnosed and, despite the absence of symptoms, it was thought advisable to determine its nature by biopsy and at the same time to explore the possibility of surgical removal.

At operation a yellowish tumour was found projecting on to the surface of the heart, its anterior limit displacing the visible part of the anterior interventricular artery and its posterior part extending to the posterior interventricular artery on the diaphragmatic surface. There was no visible tumour on the apical half of the left ventricle. Near the anterior limit of the tumour several dome-shaped nodules lay on the epicardial surface of the heart; otherwise the epicardium and pericardium were normal. These nodules were thought to be direct extensions of the tumour rather than metastases.

The tumour was much firmer than the normal cardiac tissue and gave an impression of encapsulation. Frozen-section biopsy of the tumour showed simple fibroma and it was thought possible to enucleate the tumour, still leaving sufficient left ventricle to maintain a systemic circulation. 


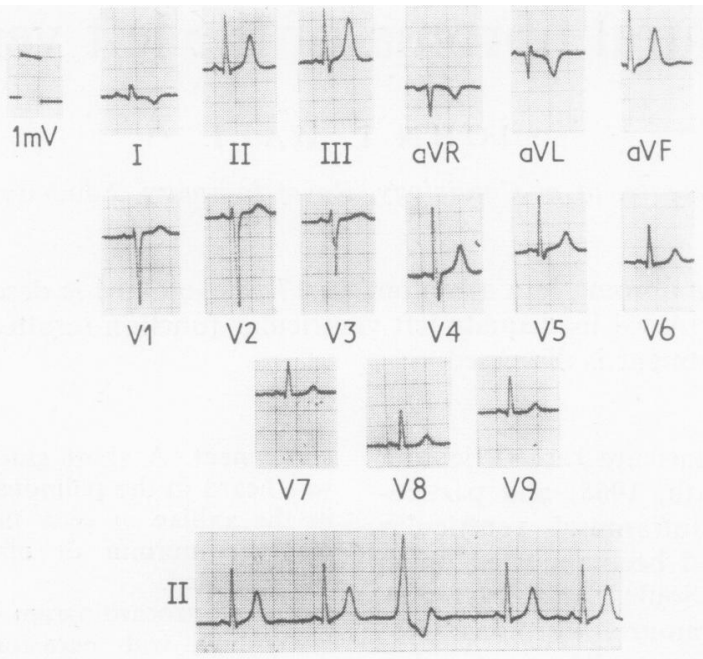

(a)

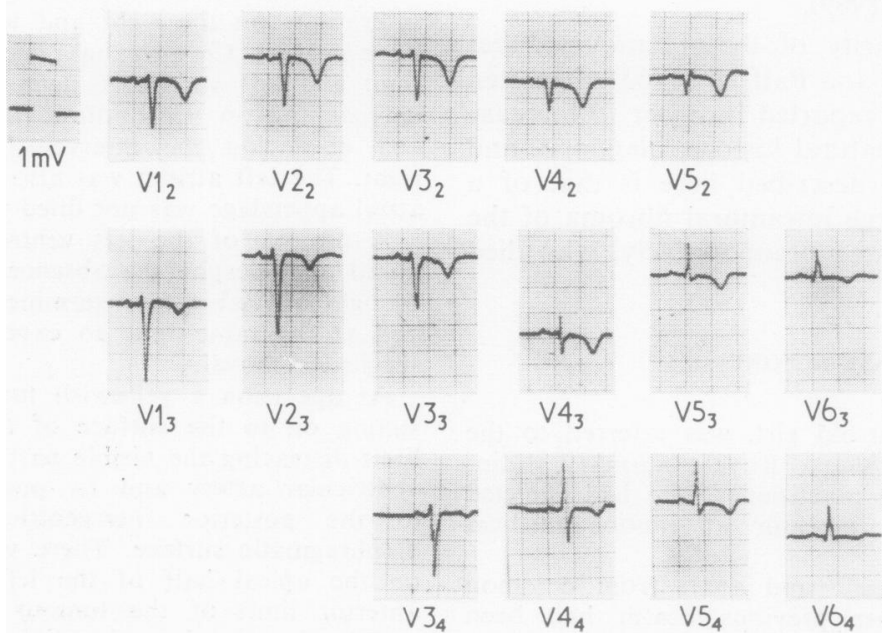

(b)

FIG. 1. (a) ECG standard leads showing symmetrical inversion of $T$ wave in I and aVL. A single ventricular extrasystole has been recorded. (b) Additional leads showing similar $T$ wave changes in the high anterolateral leads. 


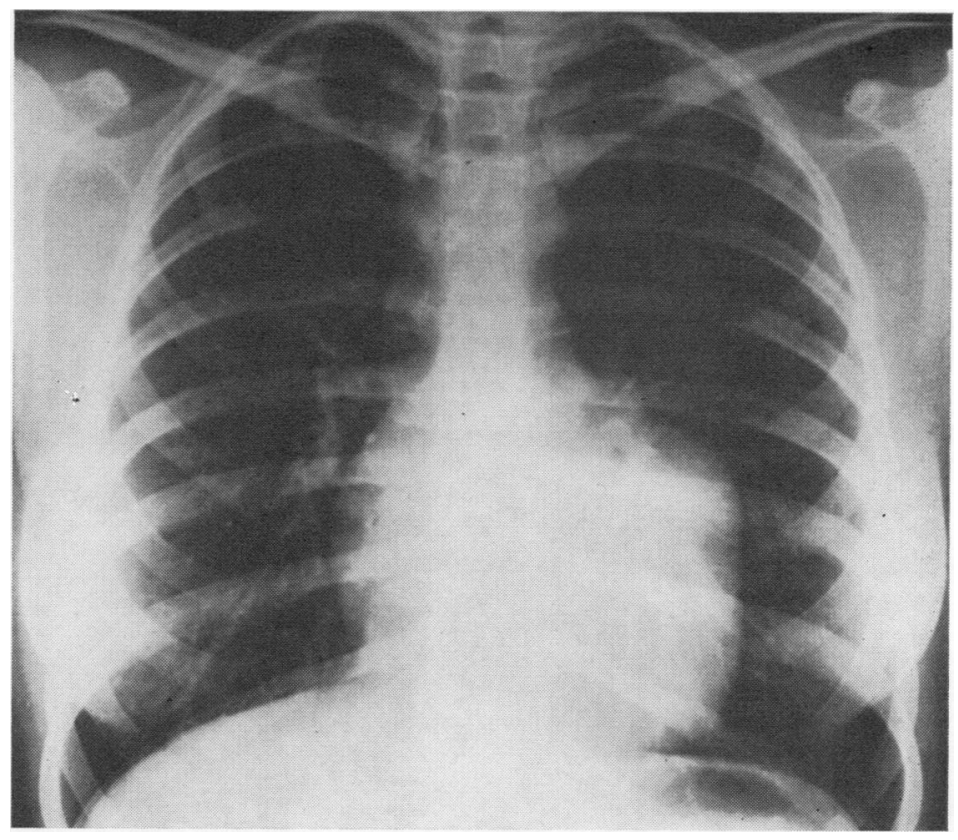

FIG. 2. Chest radiograph. PA view. Note localized bulge on upper left heart border.

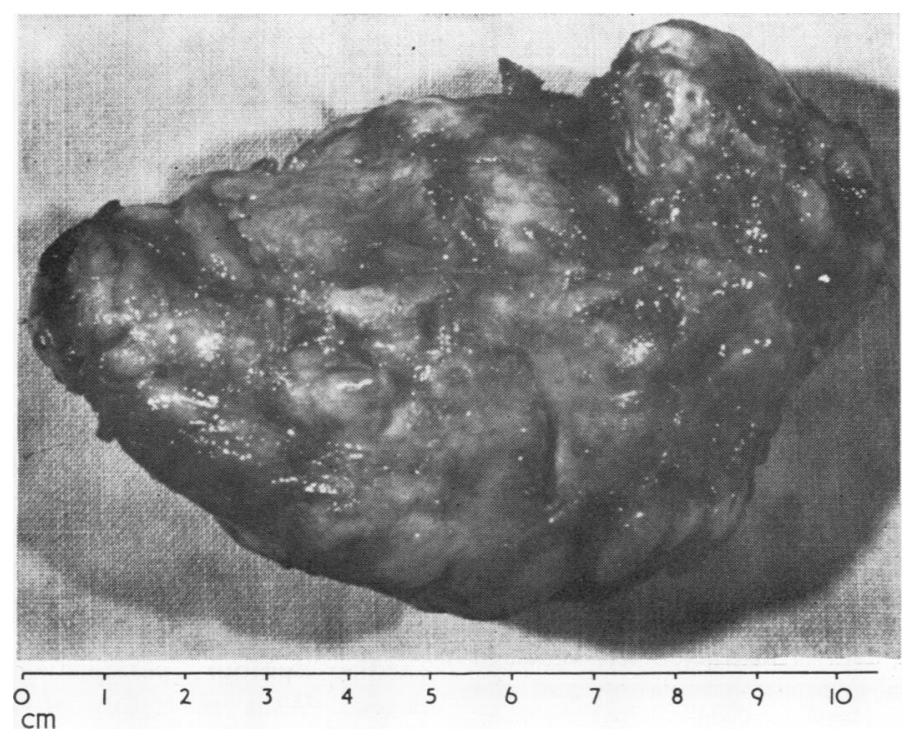

FIG. 3. Gross appearance of tumour. 


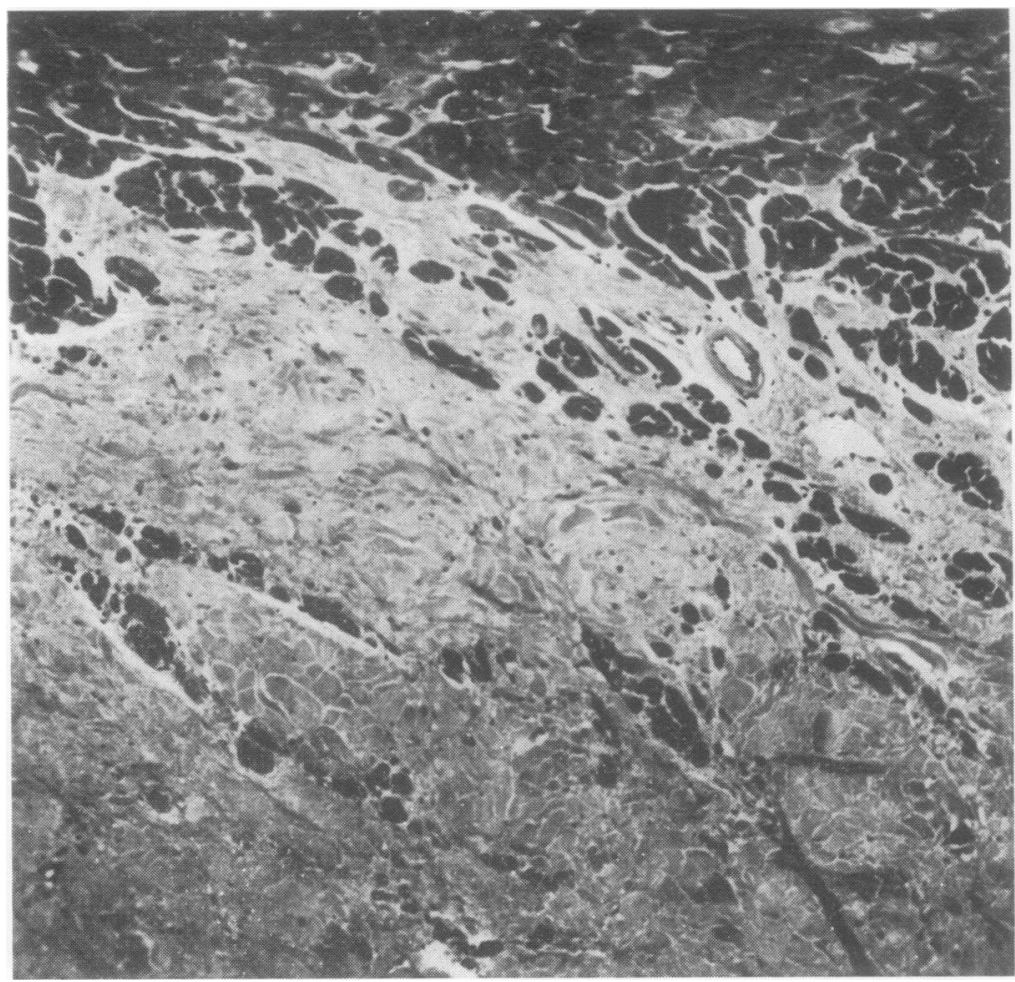

FIG. 4. Microscopic appearance of the margin of the cardiac fibroma showing the intermingling of its fibrous tissue with the surrounding myocardial fibres. $H$. and $E$. $(\times 105)$.

Bypass was then established from the venae cavae to the ascending aorta. A plane of cleavage was developed, but as dissection proceeded it became apparent that the extent of the tumour was greater than could be recognized externally. The posterior part was mobilized without entry into the cavity of the left ventricle, but the tumour extended upwards and backwards into the interventricular septum and while the visible part of the anterior interventricular artery was preserved, two major branches which passed through the tumour were divided. Full mobilization of the tumour was complicated by its close association with the aortic root. Towards the completion of the dissection, the aortic root and commissure between the right coronary and non-coronary cusps were damaged, necessitating subsequent aortic valve replacement. The left ventricular cavity was reconstructed by turning the diaphragmatic wall upwards. Repeated efforts were made to take the patient off bypass but the reconstructed left ventricle failed to maintain an adequate circulation and the patient died.

PATHology The tumour (Fig. 3) measured $10 \times 8 \times 4$ $\mathrm{cm}$ at its widest points. It was generally ovoid with irregular projections. The surface was brown, prob- $\stackrel{\mathscr{Q}}{x}$ ably representing a thin layer of resected myo- $\frac{0}{3}$ cardium.

Microscopically the tumour was a simple fibroma $\delta$ of moderate cellularity with occasional foci of $₹$ degeneration and calcification. Special stains showed 0 the intimate relationship with the myocardium at the periphery (Fig. 4). The histology of the 'satellitenodules' observed at operation was similar.

\section{DISCUSSION}

On the initial clinical findings the differential diagnosis lay between a benign pulmonary systolic murmur and mild pulmonary stenosis. The chest $\stackrel{0}{=}$ radiograph revealed a bulge on the upper left $\stackrel{\Phi}{\oplus}$ border of the heart in the region of the left atrial ${ }_{+}^{+}$ appendage and this raised the possibility of a cardiac tumour, pericardial cyst or pericardial $\overrightarrow{\mathbb{\Phi}}$ defect. With inversion of the $T$ wave in the $\frac{\rho}{\mathbb{P}}$ anterolateral leads of the ECG and occasional $\varrho$ ventricular extrasystoles, the likelihood of the lesion involving the ventricular myocardium 8 
became apparent. Angiography confirmed the presence of a mass involving the left ventricular wall.

Abnormalities of the ECG in cases of intramural fibroma include left ventricular hypertrophy and strain (Valledor et al., 1960 ; Parks et al., 1962; Hoen and Ellis, 1966), conduction defects (Jernstrom and Cremin, 1959 ; Edlund and Holmdahl, 1957), and cardiac arrhythmias (Jernstrom and Cremin, 1959). The appearance of pathological $Q$ waves in leads over the site of the tumour has also been reported (Švejda and Tomášek, 1960 ; Osano et al., 1969).

The importance of cardioangiography in the investigation of patients with cardiac tumours has been emphasized (Geha et al., 1967). It clarified the diagnosis and revealed the extent of the tumour in the present case. Although coronary angiography was not performed, this might have proved useful in demonstrating displacement of the main coronary arteries or their involvement in the tumour.

Experience of intramural ventricular fibroma is very limited. The majority of reported cases have been in infancy and early childhood but there have been a few reports of cases in older children and in adults (Geha et al., 1967). Sudden unexpected death occurred in about one-third of cases, particularly in the very young, while about half the cases had symptoms and signs of heart disease. In the remainder the tumour was found at necropsy and may not have contributed to death. Most intramural fibromas are situated in the left ventricular wall or interventricular septum and only occasionally lie in the wall of the right ventricle.

Surgical removal of these tumours has been advocated (Geha et al., 1967) and this has been successful in infants (Parks et al., 1962; Geha et al., 1967 ; Björk et al., 1967) and young children (Kay et al., 1968 ; Osano et al., 1969). One 17-month-old infant died shortly after complete removal of the tumour (Wilson et al., 1965). In others the extent of the tumour revealed at thoracotomy precluded removal, but, despite this, some of these patients had remained well for over a year following operation (Bickford, Egan, and Bryce, 1956 ; Edlund and Holmdahl, 1957 ; Hoen and Ellis, 1966).

The few reports of this type of cardiac tumour in adults suggest that the prognosis of this 17year-old girl might have been much better than we had assumed. The nature of the tumour had to be established but, in retrospect, it might be questioned whether complete removal should have been attempted once histological examination had revealed its benign nature and exploration had shown the extent to which the left ventricle was involved. Many years might have elapsed before this slow growing tumour produced ventricular dysfunction and disabled the patient. It may be that surgical treatment should have been postponed until the onset of symptoms or signs of important ventricular outflow obstruction, and that operation in adults should be directed to relief of obstruction rather than to radical removal of the tumour.

I am grateful to Dr. R. M. Marquis for permission to publish this case and for helpful advice and constructive criticism. I am also indebted to other colleagues for their assistance in the preparation of this paper.

\section{REFERENCES}

Bickford, B. J., Egan, M., and Bryce, A. G. (1956). Surgical treatment of tumours of the heart. Brit.J. Surg., 43, 514.

Björk, V. O., Dahlgren, S., Rudhe, U., and Zetterqvist, P. (1967). Fibroma in the interventricular septum of the heart. Successful removal in a 13-month-old infant. Scand. J. thorac. cardiovasc. Surg., 1, 191.

Edlund, S., and Holmdahl. K. (1957). Primary tumour of the heart: report of a case. Acta paediat. scand., 46, 59.

Freeman, J. A., Geer, J. C., Randall, W. S. Jr., and Palfrey, W. G. (1963). Intramural fibroma of the heart. Amer. J. clin. Path., 39, 374.

Geha, A. S., Weidman, W. H., Soule, E. H., and McGoon, D. C. (1967). Intramural ventricular cardiac fibroma. Circulation, 36, 427.

Heath, D. (1968). Pathology of cardiac tumors. Amer. J. Cardiol., 21, 315.

Hoen, A. G., and Ellis, E. J. (1966). Intramural fibroma of the heart. Amer. J. Cardiol., 17, 579.

Hudson, R. E. B. (1965). Cardiovascular Pathology, vol. 2, p. 1563. Edward Arnold, London.

Jernstrom, P., and Cremin, J. H. (1959). Intramural fibroma of the heart. Amer. J. clin. Path., 32, 250.

Kay, J. H., Irwin, G., Tsuji, H. K., Dykstra, P., and Magidson, O. (1968). Successful excision of an intramural fibroma of the right ventricle and ventricular septum. 4 year follow-up. J. cardiovasc. Surg. (Torino), 9, 434.

Osano, M., Yashiro, K., Oikawa, T., Takeuchi, Y., Matsuo, N., Inove, T., Nagai, I., and Yamamoto, H. (1969). Intramural fibroma of the heart. A case report. Pediatrics, 43, 605.

Parks, F. R., Jr., Adams, F., and Longmire, W. P., Jr. (1962). Successful excision of a left ventricular hamartoma. Circulation, 26, 1316.

Prichard, R. W. (1951). Tumors of the heart: review of the subject and report of 150 cases. Arch. Path., 51, 98.

Švejda, J., and Tomášek, V. (1960). Fibrous hamartoma or so-called fibroma of the myocardium. J. Path. Bact., $80,430$.

Valledor, T., Borbolla, L., Satanowsky, C., Prieto, E., Sanchez, G., Aguirre, F., Junco, J., and Palacio, A. Garcia (1960). Fibroma of the heart: case report. Dis. Chest, 37, 698.

Wilson, J. B., Hood, R. H., Johnson, H. H., Jr., Green, A. E., Jr., and Bauermeister, M. L. (1965). Primary myocardial fibromas: report of 2 cases. Radiology, 84, 1076. 